\title{
Drugs Dosing in Geriatric Patients Depending on Kidney Function Estimated by MDRD and Cockroft-Gault Formulas
}

\author{
Małgorzata Szymala-Pędzik (D) \\ Joanna Źórawska (iD ' \\ Jacek Ciach iD ${ }^{2}$ \\ 'Department of Geriatrics, Wroclaw \\ Medical University, Wrocław, Poland; \\ ${ }^{2}$ Department of Human Morphology and \\ Embryology, Wroclaw Medical University, \\ Wrocław, Poland
}

Introduction: According to the current data, regardless of the method used to estimate GFR, the differences between the obtained results should be insignificant and do not imply therapeutic decisions. The aim of this study was to analyze and compare the eGFR results with the estimated creatinine clearance score calculated according to the Cockroft-Gault equation, and to assess the significance of the difference between these two results.

Sample and Methods: A study group was constituted of 115 patients, of whom 76 were women and 39 men at the age range of 55-93 years, with a median of 79 years. The study analyzed differences in the assessment of kidney function by comparing the results of eGFR assessed by MDRD method obtained from the laboratory with the calculated values of creatinine clearance using the Cockroft-Gault formula, and examining the correlation between the difference $\mathrm{D}=\mathrm{eGFR}-\mathrm{eClCr}$ and $\mathrm{BMI}$ and body surface.

Results: In the entire group of patients $(\mathrm{N}=115)$, the significant statistical difference was found between eGFR and eClCr. In the subgroup of patients $(\mathrm{N}=45)$ with the lower baseline eGFR $<60$, there was no significant difference between eGFR and eClCr, while in the subgroup of patients with baseline eGFR $\geq 60(\mathrm{~N}=75)$, there was a significant difference between eGFR and eClCr. The study showed that based on the estimated GFR using both methods (C-G and MDRD), 29.2\% and 32.4\% of patients, respectively, were incorrectly assigned to given stage of chronic kidney disease.

Conclusion: Proper assessment of kidney function is very important in order to properly drugs dosing, especially to adjust the doses of drugs metabolized by the kidneys in order to avoid or minimize their nephrotoxic effects.

Keywords: geriatric patients, kidney function, drug dosing

\section{Introduction}

According to epidemiological data presented by the National Kidney Foundation, chronic kidney disease (CKD) affects about $11 \%$ of adults over 20 years of age, ${ }^{1}$ which accounts in the Polish population for about $4 \mathrm{mln}$ people. According to the other registers, the patients' number may be between $10 \%$ and $18 \%$ of the population, ${ }^{2-4}$ and in groups at risk of coexisting diabetes, hypertension, atherosclerosis, obesity, or in elderly patients, it may even reach $50 \%$ of the general population. $^{3}$

$\mathrm{CKD}$ is a chronic, progressive and initially asymptomatic disease, therefore some patients are unaware of the existing burden. Some of them will require renal replacement therapy in the future, so it is important to emphasize the importance of
Correspondence: Joanna Żórawska Department of Geriatrics, Wroclaw Medical University, Wrocław, Poland Email joannazor@interia.pl 
diagnosis, control and education as well as nephroprotective activities, including avoiding the use of nephrotoxic drugs and their correct dosage. ${ }^{1}$

The concept of chronic kidney disease as a set of symptoms associated with the damage or reduction of the number of nephrons was developed in 2002 by a group of American nephrologists associated with the Kidney Disease Outcome Quality Initiative (NKF K/DOQI). ${ }^{5}$ The current definition of chronic kidney disease, approved by Kidney Disease Improving Global Outcome (KDIGO) in 2005 and modified in 2012, assumes the demonstration of impaired renal function (in laboratory blood or urine tests) or their structure (abnormalities in tests imaging or histological examinations) resulting from permanent damage or depletion of nephrons due to diseases affecting the renal parenchyma. ${ }^{1,5}$

The glomerular filtration rate GFR and albuminuria are used to assess renal function. ${ }^{2,6}$ Glomerular filtration is a hypothetical amount of plasma purified from a specific substance in a given unit of time. ${ }^{7}$ A method that allows to obtain very accurate results is the assessment of the clearance using exogenous substances such as inulin or iohexal, but due to cost and invasiveness it is not widely used and is rather applied as a reference in scientific research. $^{7}$

The results obtained in the determination of creatinine clearance, which as an endogenous substance formed in the muscles, is excreted both by glomerular filtration and up to $20 \%$ by tubular secretion, may be somewhat inaccurate, and the test requires a daily urine collection. ${ }^{8-10}$

A huge progress in diagnostics was the introduction of complex mathematical equations allowing the estimation of GFR values on the basis of a single blood creatinine concentration, taking into account variables such as age, sex and body weight of the examined person. (CockroftGault method) or age, gender and race (MDRD-simplified formula) and in the case of MDRD-6: age, gender, race, creatinine, urea and albumin concentration, enabling simple and quick results. ${ }^{3,7}$

The first equation to estimate creatinine clearance $(\mathrm{CrCl})$ from blood creatinine concentration was the Cockroft-Gault formula, published in 1976, based on data from 249 male patients aged 18-92 years with measured creatinine clearance in the range of $30-130 \mathrm{~mL} / \mathrm{m}^{2} .{ }^{11,12}$ It is based on age, weight, serum creatinine and gender (Table 1). The obtained results were compared with the means of two measurements of daily creatinine clearance.
Table I The Cockcroft-Gault Formula for Estimating Creatinine Clearance $(\mathrm{CrCl})^{11,12}$

\begin{tabular}{|l|l|}
\hline & \multicolumn{1}{|c|}{ CrCl } \\
\hline $\begin{array}{l}\text { Male } \\
\text { Female }\end{array}$ & $([$ l40-age $] \times$ weight in $\mathrm{kg}) /($ serum creatinine $\times 72)$ \\
\hline
\end{tabular}

The method does not take into account the size of the body surface area. ${ }^{13}$

Currently, the GFR value calculated according to the Cockroft-Gault formula is not generally recommended for the diagnosis and monitoring a course of chronic kidney disease. $^{5,14}$ The Cockroft-Gault equation underestimates the GFR value in lean and elderly people, and overstates the obese and hyperhydrated people. ${ }^{7}$

It should be, yet, emphasized that on the basis of the GFR calculated according to the Cockroft-Gault formula the pharmacokinetic studies related to the registration of drugs were carried out to determine the dosage in patients with kidney disease. ${ }^{15-17}$

The MDRD formula was introduced in 1999 based on data analysis of 1628 patients with chronic kidney disease (mean GFR $40 \mathrm{~mL} / \mathrm{min} / 1.73 \mathrm{~m}^{2}$ ) who were predominantly Caucasian and had no associated diabetes. ${ }^{18}$ This formula comes in two forms - the classic one, which takes into account such variables as age, sex, race, serum creatinine, urea and serum albumin (MDRD6), and a simplified one that takes into account only age, gender, race and creatinine concentration (the so-called MDRD4), which has found widespread use in the assessment of e GFR. ${ }^{18,19}$

MDRD formula: GFR $\left(\mathrm{mL} / \mathrm{min} / 1.73 \mathrm{~m}^{2}\right)=175 \times$ $\left(\mathrm{S}_{\mathrm{cr}}\right)^{-1.154} \times(\mathrm{Age})^{-0.203} \times(0.742$ if female $) \times(1.212$ if African American) (conventional units). ${ }^{20-22}$

To date, the MDRD equation has been evaluated in a number of further patient populations, including: African Americans, Europeans, and Asians, as well as diabetic patients with and without underlying kidney disease, kidney transplant patients, and potential kidney donors. ${ }^{14}$ Observations have shown that the MDRD formula is a good tool in everyday clinical practice to assess kidney function. ${ }^{3,5}$

It should be noted, however, that the MDRD formula has not been tested in persons without confirmed kidney damage (without demonstrated albuminuria), in pregnant women, in children, in the elderly $>85$ years of age, and in some ethnic groups, eg, Latinos. Nevertheless, the commonness and ease of obtaining the eGFR result contributed 
to a significant improvement in the diagnosis and monitoring of chronic kidney disease. ${ }^{16}$

However, it should be emphasized that the MDRD formula underestimates the results in the GFR range of 60-120 $\mathrm{mL} / \mathrm{min}$ range. Therefore, the MDRD equation for GFR $>60 \mathrm{~mL} / \mathrm{min} / 1.73 \mathrm{~m}^{2}$ by lowering the values may lead to a misdiagnosis of CKD in healthy persons. ${ }^{7}$

In 2009, Levey at all developed another equation to evaluate the eGFR, namely CKD-EPI. ${ }^{23,24}$ This time, a much larger group of subjects was included -8254 both healthy and those with kidney disease. The same data as for the simplified version of MDRD (age, sex, race, creatinine concentration) are required to assess e GFR. It has been shown that it has a very similar accuracy compared to MDRD in the case of GFR $<60 \mathrm{~mL} / \mathrm{min} / 1.73 \mathrm{~m}^{2}$, and higher accuracy for GFR $>60 \mathrm{~mL} / \mathrm{min} / 1.73 \mathrm{~m}^{2}$. ${ }^{19,24}$

In line with the recommendations of KDIGO (2012), CKD-EPI (named after the Chronic Kidney Disease Epidemiology Collaborative) is currently the preferred method for determining the estimated GFR. However, some researchers discuss the above recommendation, proving the benefits of the commonly used MDRD formula and the CDI-EPI inaccuracy in the case of low GFR values. $^{25}$

In everyday clinical practice, most determinations are still made using the MDRD equation. At the same time, it is known that the incidence of chronic kidney disease and renal failure increases in the elderly. The most common causes are the coexistence of diseases leading to kidney damage, such as atherosclerosis, arterial hypertension, diabetes type 2, also the use of nephrotoxic drugs and prerenal damage associated with chronic fluid deficiency. ${ }^{2,6}$

It should also be mentioned here that the pathological processes overlap with the slow deterioration of the excretory function of the kidneys associated with the aging process of organs due to atherosclerotic lesions, atrophy of the renal tubules and glomerular sclerosis. ${ }^{2,26}$ After the age of 30 years, there is a decrease in GFR ca. $1.0 \mathrm{~mL} / \mathrm{min}$ yearly. ${ }^{2}$

In the physiological aging process, both macroscopic changes (thinning of the renal cortex, more frequent occurrence of simple cysts) and microscopic changes, like a decrease in the number of active nephrons on the basis of atherosclerosis, interstitial fibrosis and atrophy of the renal tubules, are observed. ${ }^{27}$

Biopsy studies conducted in healthy kidney donors have shown that nephron sclerosis can be observed only in about $2.7 \%$ of donors aged $<30$ years, but in about $58 \%$ in the case of donors aged $60-69$ years and in $73 \%$ of donors over 70 years of age life. The physiological decrease in the number of nephrons and the associated reduced GFR index, compared to people aged 18-29 and $70-75$ years of age, can amount to as much as $48 \%{ }^{27}$

It should be emphasized that, as Hommos et al reported, ${ }^{27}$ the mere demonstration of a reduced eGFR value, indicating the existence of chronic kidney disease $\left(<60 \mathrm{~mL} / \mathrm{min} / 1.73 \mathrm{~m}^{2}\right)$, with the simultaneous lack of albuminuria does not translate into an increased risk of death for a given age group. ${ }^{28}$

In a study comparing the results of eGFR and eClCr with the reference methods of assessing GFR in most patients and in most of the drugs used, the differences obtained in the results of eGFR and eCrCl are so small that they do not lead to the need for significant changes in drug dosage. In principle, any method of GFR determination can be used. ${ }^{28}$ The exception seems to be patients with a body surface that differs significantly from the standard one, ${ }^{29-31}$ where these differences may be significant.

Moreover, it is worth noting the specificity of therapy in geriatric patients resulting from multimorbidity with subsequent polypharmacy, more frequent occurrence of $\mathrm{CKD}$, as compared to the general population, as well as the above-mentioned difference, significant for drug dosing, between the eGFR and eCrCl results in patients with body surface area significantly different from the mean population values. Taking all of this into consideration, the authors decided to undertake the present analyses in order to ascertain for which patient drug dosing should be determined using the eClCr values calculated with the Cockroft-Gault formula instead of the eGFR results obtained from the laboratory.

\section{Sample and Methods}

For this analysis, retrospective data from 115 patients hospitalized at the Department of Geriatrics of the University Hospital in Wrocław in 2020 were used. The results of 76 women and 39 men were included in the study. The minimum age of patients is 55 years, the maximum age is 93 years with a median of 79 years.

The study analyzed differences in the assessment of kidney function by comparing the results of eGFR assessed by MDRD method obtained from the laboratory with the calculated values of creatinine clearance using the Cockroft-Gault formula, and examining the correlation between the difference $\mathrm{D}=\mathrm{eGFR}-\mathrm{eClCr}$ and $\mathrm{BMI}$ and body surface. 


\section{Statistical Analyses}

The normality of the distributions was tested with the Shapiro-Wilk test. The difference between eGFR and $\mathrm{eClCr}$ in the whole study group - the Wilcoxon test, and the "loess method: local regression fitting" method were used to determine the regression line. Calculations were made using the program: The $\mathrm{R}$ Project for Statistical Computing - R, v. 4.0.3- R Studio, v. 1.4.1103.

The study was approved by the Commission of Bioethics at Wroclaw Medical University (KB-58/2021). All patients gave their informed consent to participate in the study. The study was performed in accordance with the principles of the Declaration of Helsinki.

\section{Results}

A study group was constituted of 115 patients, of whom 76 were women and 39 men at the age range of 55-93 years, with a median of 79 years (Table 2)

The minimum GFR (estimated creatinine clearance eClCr) calculated from the Cockroft-Gault formula was $19.11 \mathrm{~mL} / \mathrm{min}$, and the maximum was $123.31 \mathrm{~mL} / \mathrm{min}$ with a median of $62.51 \mathrm{~mL} / \mathrm{min}$, and a range of 104.2 $\mathrm{mL} / \mathrm{min}$ (Table 2).

In addition, the analysis assessed the number of chronic medications used by patients (short-term medications, reliever medications, vitamins, supplements and topical medications were not included). The minimum number of continuous medications was 2 and the maximum was 13, with a median of 7 (Table 2).

Moreover, the number of drugs requiring dose adjustment or drug discontinuation in the case of renal failure was assessed. The following drugs: antidiabetic (metformin, sulfonylureas), NOAC drugs, NSAIDs, pregabalin, ACEI, diuretics, and in one case chronically used LMWH) were considered as nephrotoxic. The minimum number of these drugs used by patients was 0 and the maximum was 5 , with a median of 2 (Table 2 ).

The differences in the assessment of kidney function were analyzed by comparing the eGFR results obtained from the laboratory using the MDRD method with the calculated values of creatinine clearance using the Cockroft-Gault formula. The correlation between the difference $\mathrm{D}=\mathrm{eGFR}$ - eClCr and $\mathrm{BMI}$ and body surface was also investigated.

In the entire group of patients ( $\mathrm{N}=115)$, the significant statistical difference was found between eGFR and eClCr $\left(\mathrm{p}<10^{-4}=0.0001\right)$. In the subgroup of patients $(\mathrm{N}=45)$ with the lower baseline eGFR $<60$, there was no significant difference between eGFR and eClCr $(\mathrm{p}=0.48)$, while in the subgroup of patients with baseline eGFR $\geq 60$ ( $N=$ 75), there was a significant difference between eGFR and eClCr $\left(\mathrm{p}<10^{-5}\right)$.

The further analysis also proved the existence of a statistical relationship between the difference $\mathrm{D}=\mathrm{eGFR}$ - eCrCl in correlation to BMI and body surface area (Figures 1-4). There is a statistically strong (rho close to -1 ) inverse correlation between D and BMI and between $\mathrm{D}$ and body surface area. As the BMI or body surface area increases, the eClCr values start to exceed the eGFR values. The regression lines in the Figures 1 and 2 were determined using the LOESS "loess method: local regression fitting" method. The points where the value determined by the local regression reaches the minimum, ie, where the eGFR and $\mathrm{eClCr}$ are the closest to each other, are the values of $30.8 \mathrm{~kg} / \mathrm{m}^{2}$ for the BMI and $1.95 \mathrm{~m}^{2}$ for the body surface area. The further from the above-mentioned points, the greater the difference between the obtained results, and with an increase in the BMI or body surface area, the eClCr values start to exceed the eGFR, while in the range of values lower than the minimum regression, both in terms of BMI data and body

Table 2 Results of the Study

\begin{tabular}{|l|c|c|c|c|}
\hline Results & Minimum Value & Maximum Value & Median & Range \\
\hline Patients' age & 55 years & 93 years & 79 years & $26.73 \mathrm{~kg} / \mathrm{m}^{2}$ \\
BMI value & $16.28 \mathrm{~kg} / \mathrm{m}^{2}$ & $43.87 \mathrm{~kg} / \mathrm{m}^{2}$ & $1.83 \mathrm{~m}^{2}$ & $0.9 \mathrm{mg} / \mathrm{dl}$ \\
Body surface area & $1.23 \mathrm{~m}^{2}$ & $2.56 \mathrm{~m}^{2}$ & $1.97 \mathrm{mg} / \mathrm{dl}$ \\
Creatinine concentration & $0.49 \mathrm{mg} / \mathrm{dl}$ & $2.26 \mathrm{mg} / \mathrm{dl}$ & $70 \mathrm{~mL} / \mathrm{min} / 1,73 \mathrm{~m}^{2}$ & $110 \mathrm{~mL} / \mathrm{min}^{2} / .73 \mathrm{~m} 2$ \\
eGFR & $21 \mathrm{~mL} / \mathrm{min} / 1.73 \mathrm{~m}^{2}$ & $131 \mathrm{~mL} / \mathrm{min} / 1.73 \mathrm{~m}^{2}$ & $62.5 \mathrm{~mL} / \mathrm{min}$ & $104.2 \mathrm{~mL} / \mathrm{min}$ \\
CICr by C-G formula & $19 \mathrm{~mL} / \mathrm{min}$ & $123.31 \mathrm{~mL} / \mathrm{min}$ & 7 & \\
Number of drugs used continuously & 2 & 13 & 2 & \\
Number of drugs metabolized by the kidneys & 0 & 5 & & \\
\hline
\end{tabular}




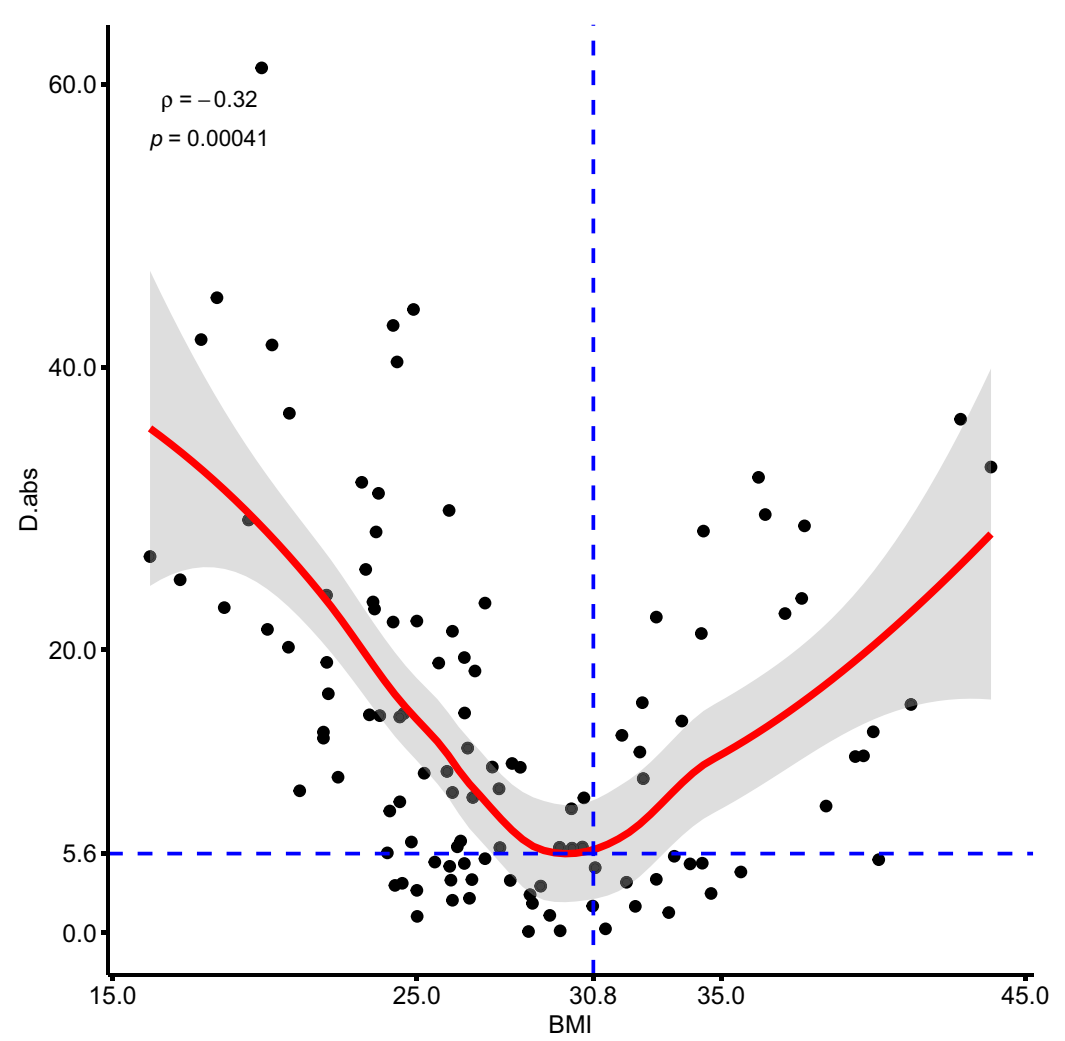

Figure I The relationship between the absolute value of $\mathrm{D}$ (difference eGFR -eCICr) - Y axis and BMI - $\mathrm{X}$ axis. The red line represents the local regression.

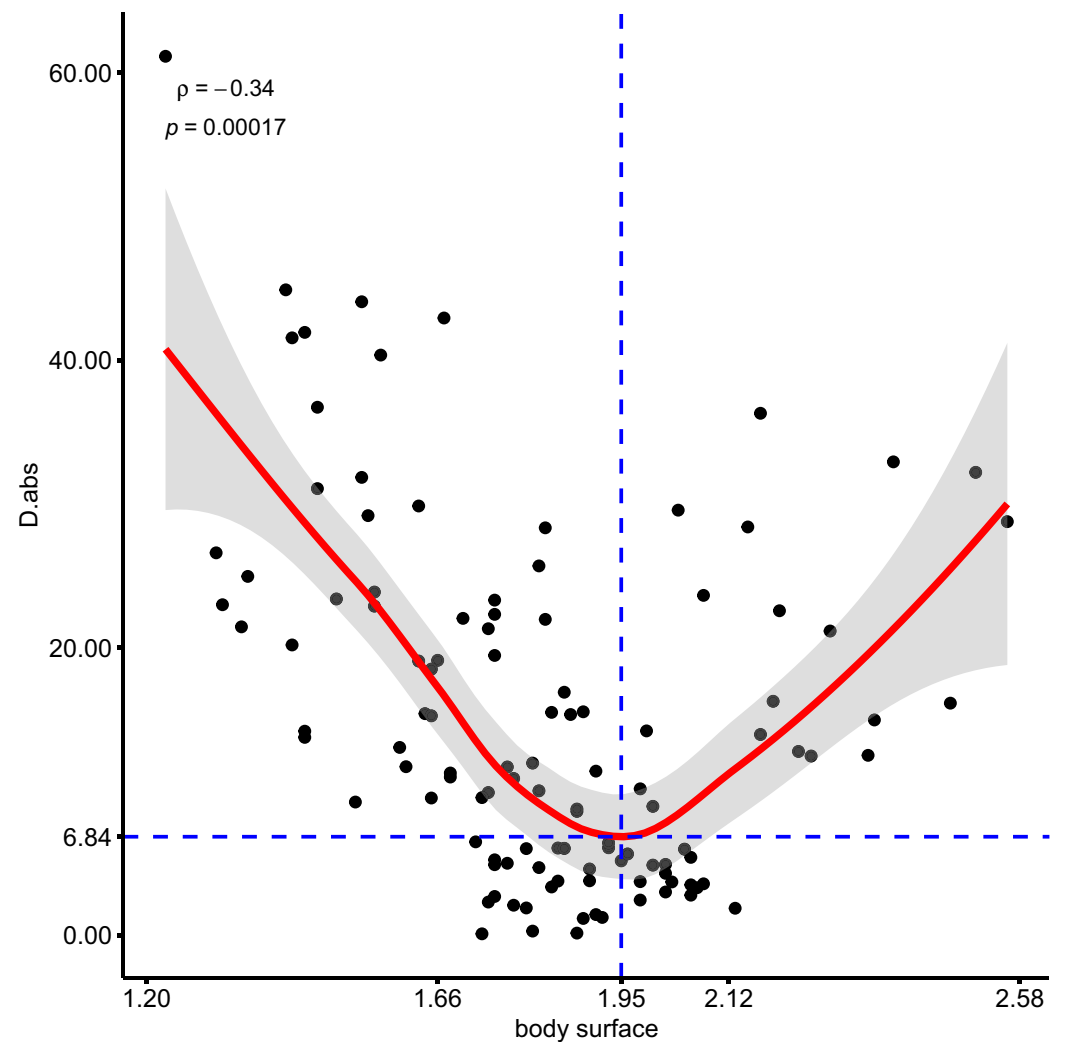

Figure 2 The relationship between the absolute value of $D$ (difference eGFR -eClCr) - Y axis, and body surface area - $X$ axis. The red line represents the local regression. 


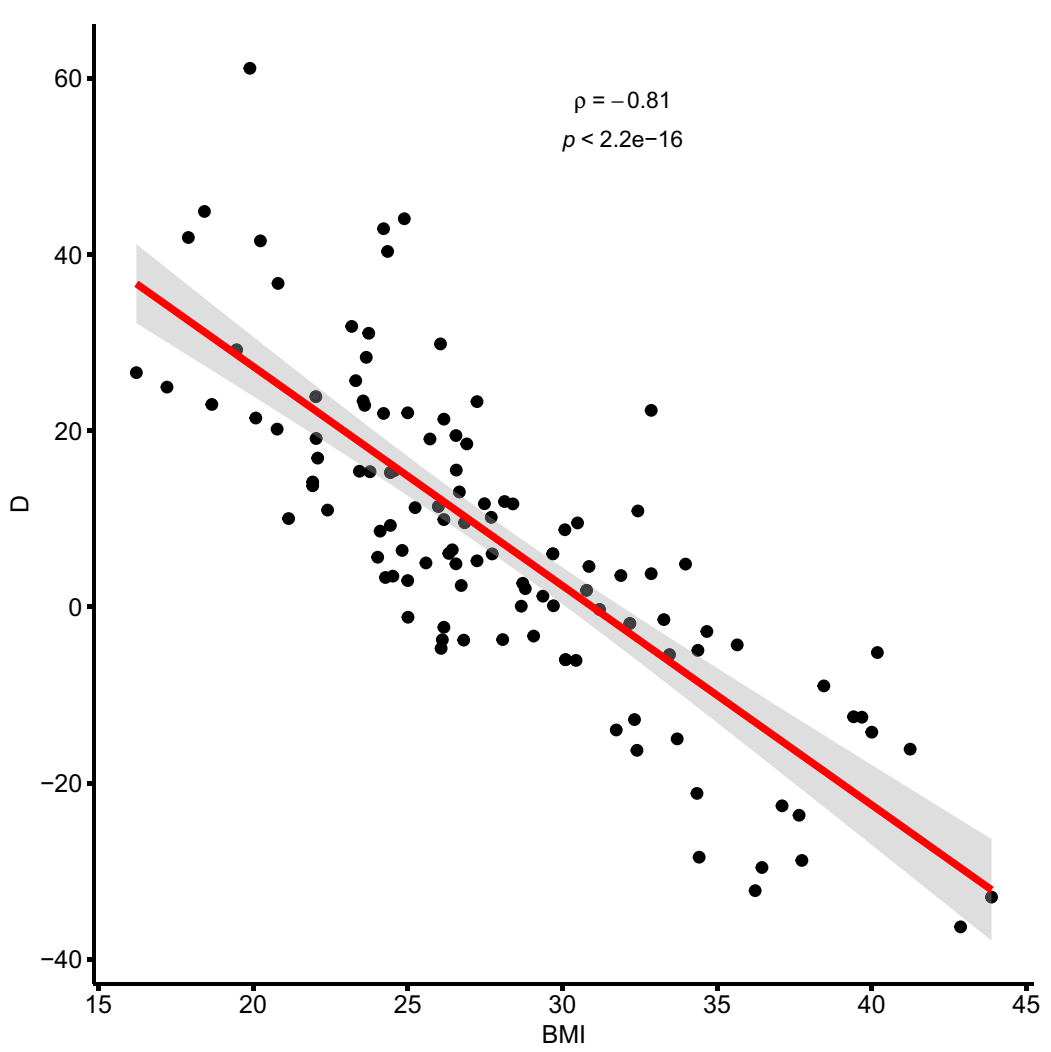

Figure 3 The relationship between the value D (difference eGFR - eCICr) - Y axis, and BMI - X axis. The red line represents the local regression.

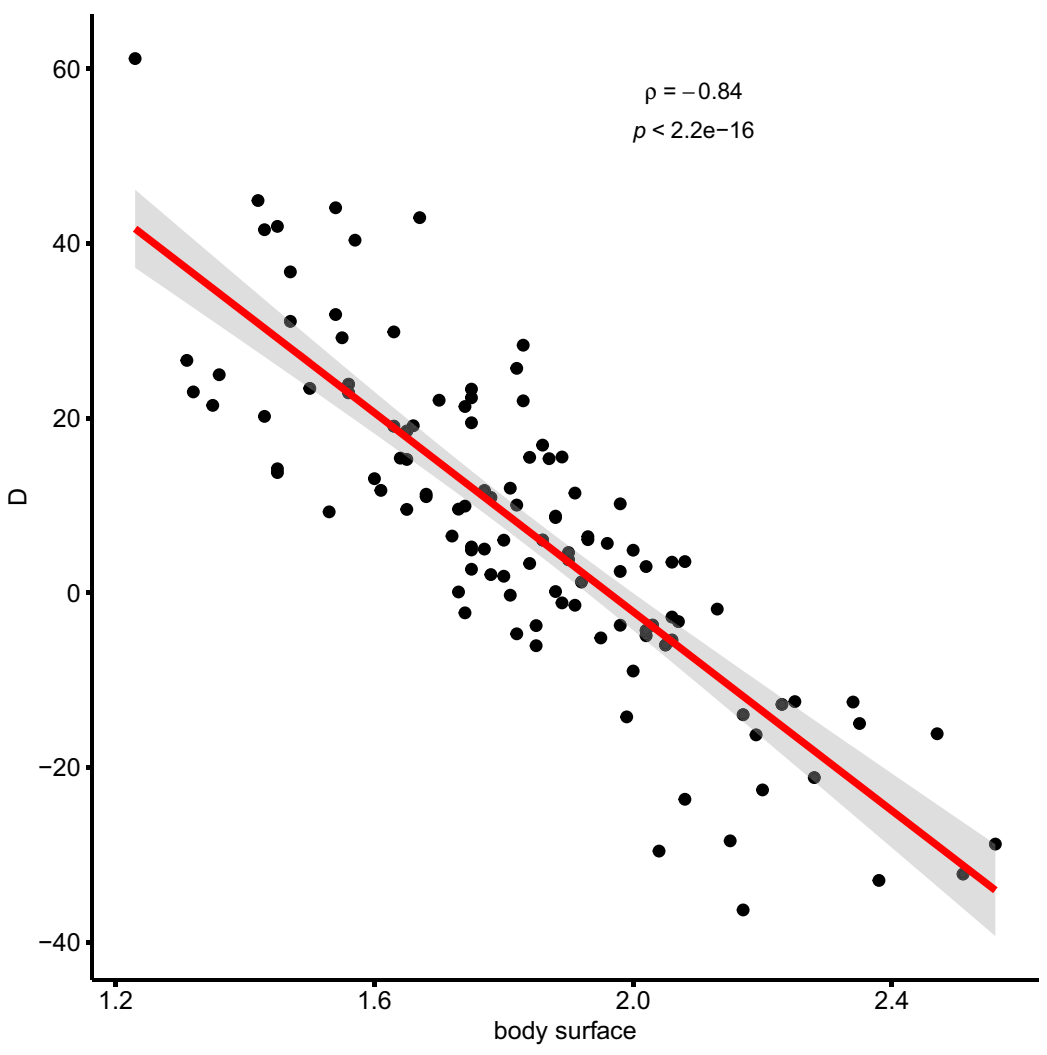

Figure 4 The relationship between the value $D$ (difference eGFR - eClCr) - Y axis, and body surface area - $\mathrm{X}$ axis. The red line represents the local regression. 
surface area the value $\mathrm{eClCr}$ is smaller than eGFR (Figures 1-4).

The above observation also analyzed the amount of drugs used chronically by patients, where the minimum number of constantly used drugs was 2 and the maximum 13 with a median of 7 , including the number of drugs metabolized by the kidneys with the potential to deteriorate kidney function, especially in the case of incorrect dosing, from 0 to 5 with a median of 2 . In order to prevent chronic kidney disease and slow its progression, it is necessary to carefully analyze the drugs used, avoid polytherapy and avoid nephrotoxic drugs. The data collected in our study included: gender, age, weight, height, creatinine, eGFR, fCG, number of drugs taken, including the number of drugs known to be nephrotoxic. Based on the above data, BMI and body surface area (BSA) were calculated according to the formulas:

BMI $=$ body mass $(\mathrm{kg}) /$ height $^{2}(\mathrm{~m})$ and BSA by Haycock $=0.024265 . h 0.3964 . w 0.5378$.

Multiple linear regression was performed for the dependent variable $\mathrm{D}=\mathrm{eGFR}$ - fCG adjusted for confounders such as: body mass (present in the MDRD formula but not in the Cockcroft-Gault formula), the number of medications taken, and the number of nephrotoxic drugs taken.

Relationship between D and BMI: The analysis of the results of multiple regression adjusted for body mass, number of medications taken, and number of nephrotoxic medications taken showed that the difference in $\mathrm{D}$ is not influenced by the number of medications taken. Adding this information to the regression model did not change significantly $(>20 \%)$ the coefficients obtained in the model without this information. Moreover, the calculated coefficients related to the number of drugs did not have a statistically significant $(p>0.05)$ influence on the model result ( $\mathrm{D}$ value).

However, it was found that the patient's body weight is an important factor (confounder). Introducing it to the model changed the value of the coefficient for BMI by $73 \%$. A statistically significant influence of the body mass on the value of $\mathrm{D}$ was also found. It should be emphasized, however, that the patients' body weight - although absent in the Cockcroft-Gault formula, hence its consideration as a potential confounding factor - and the BMI value are directly related to each other. In order to better assess the impact of body weight and BMI on the difference "D", a larger observation group should be gathered, which would allow for the assessment of confounding factors not only by statistical methods, but also by matching and restriction. The relatively small size of the observation group is one of the limitations of our study (Figure 5).

The relationship between $\mathrm{D}$ and body surface area: As in the case of the relationship between D and BMI, the analysis of the results of multiple regression taking into account the effect of body weight and the number of drugs taken on the difference " $D$ " showed that consideration of the number of drugs in the model does not significantly change the parameters of the model. Introducing the patient's body weight to the model changes the value of the coefficient for the body area by $50 \%$. Interestingly, it also causes the surface area to cease to be a statistically significant component of the model. In the case of the dependence of $\mathrm{D}$ on the body surface area and body weight, it should also be noted that the patient's weight is directly related to the patient's body surface calculated using the Haycock formula.

Summing it up - the obtained results allow, in our opinion, to conclude that the difference $\mathrm{D}=\mathrm{eGFR}-\mathrm{fCG}$ is significantly influenced by BMI and body mass. The more the patient's BMI differs from approx. $31 \mathrm{~kg} / \mathrm{m}^{2}$ or $82.5 \mathrm{~kg}$, the greater the difference $\mathrm{D}$ is greater in the absolute value.

This can also be expressed, as follows:

for BMI $<31 \mathrm{~kg} / \mathrm{m}^{2}$ or body weight $<82.5 \mathrm{~kg}$, the difference $\mathrm{D}>0$; meaning eGFR $>$ fCG;

while for BMI $>31 \mathrm{~kg} / \mathrm{m}^{2}$ or body weight $>82.5 \mathrm{~kg}$, the difference $\mathrm{D}<0$; meaning eGFR $<$ fCG.

The study showed that based on the estimated GFR using both methods (C-G and MDRD), $29.2 \%$ and 32.4\% of patients, respectively, were incorrectly assigned to given stage of chronic kidney disease.

\section{Discussion}

Assessment of kidney function is very important in order to properly drugs dosing, especially to adjust the doses of drugs metabolized by the kidneys in order to avoid or minimize their nephrotoxic effects. ${ }^{26,28}$ The current recommendations in the Summary of Product Characteristics are mainly based on the old pharmacokinetic studies, before the era of standardization of creatinine assessment and the common use of estimated GFR, when the estimated creatinine clearance $(\mathrm{eClCr})$ calculated from the Cockroft-Gault equation was used to assess renal function. ${ }^{13,28,30}$

Historically, the use of different methods of creatinine concentration has resulted in different method-dependent 


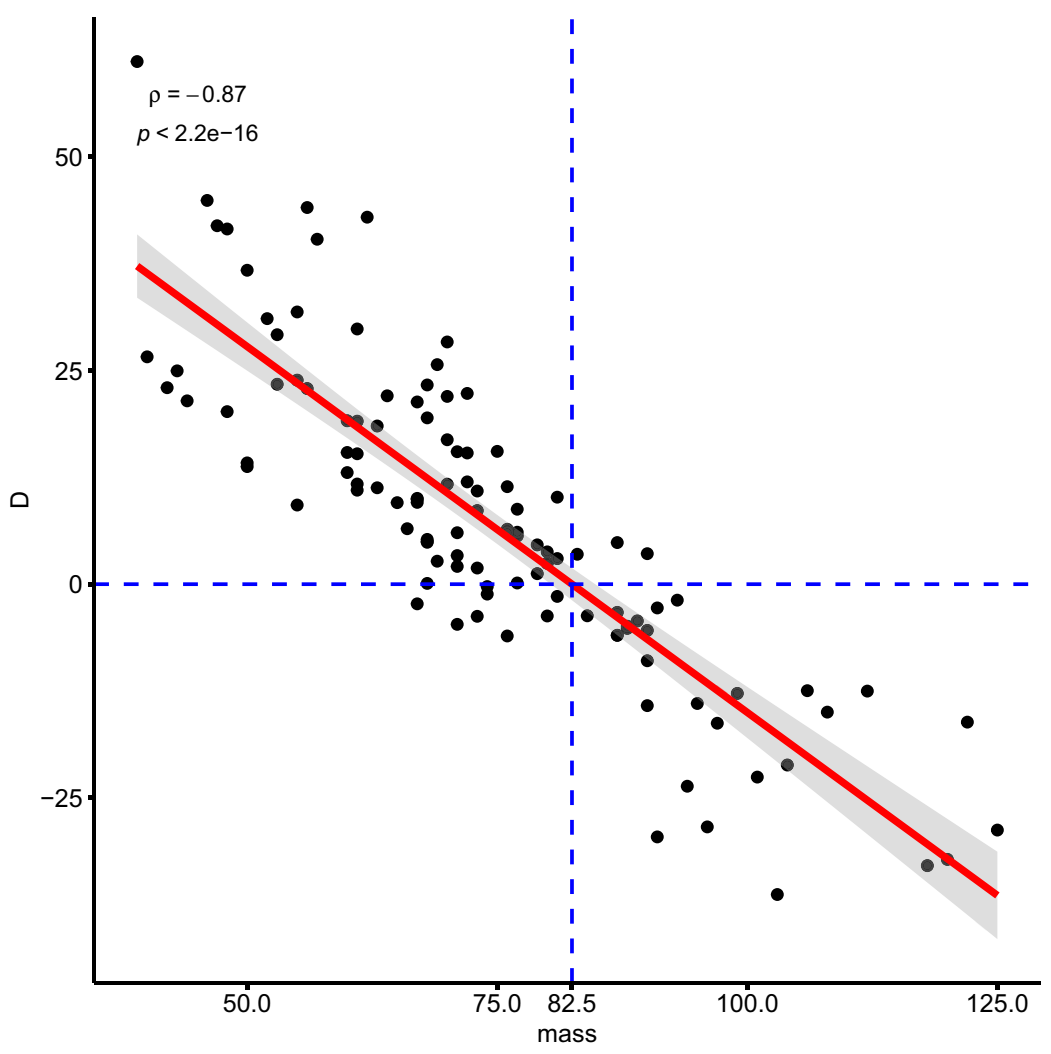

Figure 5 The relationship between the value D (difference eGFR - eClCr) - Y axis, and body mass - $\mathrm{X}$ axis. The red line represents the local regression.

results which were difficult to compare with others, yet inconsistently used in recommendations for drug dose adjustment in patients with kidney disease. The current progress in the diagnosis of kidney diseases, the widespread use of the estimated GFR filtration coefficient and the standardization of creatinine concentration assessment result in the possibility of a more precise assessment of kidney function. ${ }^{30-36}$

Perhaps, according to the current state of knowledge, on the basis of eGFR, and not eCLCr, pharmacokinetic studies of new drugs should be performed in order to ensure safer dosing of drugs, but it is difficult to imagine a situation in which manufacturers of all drugs used so far will conduct another pharmacokinetic test to update the dosing recommendations for existing drugs. ${ }^{30-36}$

The aim of this study was to analyze and compare the eGFR results with the estimated creatinine clearance score calculated according to the Cockroft-Gault equation, and to assess the significance of the difference between these two results. According to the current data, ${ }^{28,33}$ regardless of the method used to estimate GFR, the differences between the obtained results should be insignificant and do not imply therapeutic decisions.
The present study results revealed that based on the estimated GFR using both methods (C-G and MDRD), $29.2 \%$ and $32.4 \%$ of patients, respectively, were incorrectly assigned to given stage of chronic kidney disease.

The further practical conclusion is that in the population of 115 patients who underwent observation, as many as 45 people (this group constitutes $39 \%$ of the total number of respondents), the initial eGFR was $<60 \mathrm{~mL} /$ $\min / 1.73 \mathrm{~m}^{2}$. In some cases, there are no clear data on the history of the length of the lesions, so if the time criterion is not met ( $>3$ months), it is not possible to diagnose chronic kidney disease in all these patients, nevertheless this group requires periodic laboratory control in an outpatient setting. Optimizing the treatment of comorbidities as well as a careful analysis of the need for chronic drugs, especially drugs metabolized in the kidneys, and their appropriate dosage.

In the Fiossart et al's cohort study, data from 2095 adult patients were analyzed by comparing the results obtained from the Cockroft-Gault or MDRD equation with the reference creatinine clearance result. While in the overall analysis, the results between eGFR and the reference creatinine clearance were slightly different, 
regardless of the method used, the differences became more significant in the subgroup analysis taking into account age, sex and body weight. In most cases, the results of the Cockroft-Gault equation turned out to be less accurate. Fiossart et al emphasize the need to design large multicentre studies to validate equations to assess eGFR. $^{38}$

Various researchers (including Cirillo et al) emphasize limitations in the use of both methods. MDRD equation has not been validated for GFR $>60 \mathrm{~mL} / \mathrm{min}$ because the studies did not include healthy people. ${ }^{39}$ This is reflected in a study by Stevens et al comparing eGFR size according to MDRD with GFR after use of radionuclides. It was shown that eGFR from the MDRD pattern was compatible with GFR only at GFR values $<60 \mathrm{~mL} / \mathrm{min} / 1.73 \mathrm{~m}^{2}{ }^{37}$

According to the recommendations of KDIGO, the determination of the eGFR values between 60 and 89 $\mathrm{mL} / \mathrm{min} / 1.73 \mathrm{~m}^{2}$ was associated with the diagnosis of chronic kidney disease only in the presence of other markers of kidney damage. The paragraph on seniors emphasized the physiological decline in GFR associated with age and the difficulties in distinguishing the causes of a reduced GFR in the coexistence of early-stage kidney disease. $^{1,5}$

The data show that up to $75 \%$ of people over 70 years of age may have GFR $<90 \mathrm{~mL} / \mathrm{min} / 1.73 \mathrm{~m}^{2}$, and $25 \%<60$ $\mathrm{mL} / \mathrm{min} / 1.73 \mathrm{~m}^{2} .{ }^{5,29}$ Patients with a GFR result of $60-89$ $\mathrm{mL} / \mathrm{min} / 1.73 \mathrm{~m}^{2}$ should be tested for comorbidities, mainly cardiovascular disease, lipid disorders, and diabetes mellitus. With a low risk of cardiovascular disease, the main recommendations are regular checks of kidney function (at least once a year), urine sediment testing, blood pressure control, changing to an active lifestyle and avoiding drugs and contrast agents with nephrotoxic potential. ${ }^{5,29,30}$

The situation is slightly different in elderly patients with GFR $<60 \mathrm{~mL} / \mathrm{min} / 1.73 \mathrm{~m}^{2}$ or at high risk of developing or being diagnosed with cardiovascular disease. In addition to the above measures, they require assessment of CKD complications (anemia, endocrine disorders, nutritional deficiencies, osteoporosis, neuropathy) and dietary and pharmacological treatment aimed at slowing the progression of CKD and mitigating the levels of cardiovascular risk factors, regularly repeated blood and sediment test urine (up to 4 times a year) and nephrological consultation in case of disease progression. ${ }^{1,5}$

The aim of our study was to answer the question whether there is a need for additional determination of
GFR according to the Cockroft-Gault equation in order to ensure optimal drug dosing and minimize nephrotoxicity. Due to the supposed slight difference between the results obtained in the Cockroft-Gaul equation and MDRD, an attempt was made to distinguish patients in whom these differences might be more significant. It was observed that the more distant the BMI or body surface area result from the so-called minimum regression, ie, the point where both results differ slightly (in the above case BMI $30.8 \mathrm{~kg} / \mathrm{m}^{2}$, and body surface area $1.93 \mathrm{~m}^{2}$ ), the differences between eGFR and eCLCr were bigger.

It leads to the practical conclusion that in people with BMI values or body surface area significantly different from the standard ones, the eClCr values calculated according to the Cockroft-Gault equation should be used in determining the doses of drugs metabolized by the kidneys. Of course, it should be emphasized that the eGFR formula (most often calculated according to the MDRD formula) is still a standard when it comes to assessing kidney function and qualifying the patient to the appropriate stage of chronic kidney disease, while the Cockroft-Gault formula is destined to determine the exact dose of drugs according to the manufacturer's information in patients with renal failure, especially those with a body surface area or BMI significantly different from the standard ones.

According to the recommendations of nephrology societies, the prevention and treatment of chronic kidney disease requires an active approach both on the part of the patient (increased physical activity, adequate diet, hydration, avoidance of self-administered drugs, especially those metabolised by the kidneys, including NSAIDs) and the doctor (repeated at control intervals). Blood and urine tests for the assessment of kidney function and the presence of albuminuria, especially in patients at risk of chronic kidney disease, optimal treatment of comorbidities, critical analysis of the indications for the use of contrast agents, analysis of the amount of necessary drugs in chronic therapy and precise dosing of drugs metabolized by the kidneys, appropriate patient education and referral to Nephrology Clinics of patients with e GFR $<30$.

\section{Strengths and Limitations of the Study}

Strengths of this work are: addressing the important topic of assessing renal function in the geriatric population and 
paying attention to possible differences in drug dosing using the Cockroft-Gault formula as compared with MDRD equation. Limitations: the small size of the study group does not allow to separate subgroups in terms of body weight and height, age or sex, and to conduct a thorough assessment of the impact of these parameters on the difference D. This is particularly important in the context of body weight; it is a variable that appears in the CG formula but not in the MDRD equation. The spread of body weight in the examined patients is quite significant: from $39 \mathrm{~kg}$ to $125 \mathrm{~kg}$, with the coefficient of variation equal to $24 \%$, which, considering the number of all patients (115), makes it impossible to separate appropriately numerous subgroups with similar body weight. In the light of the data obtained in the present study, it is worthwhile in patients with BMI or body surface significantly different from the standard one to calculate $\mathrm{ClCr}$ with the Cockroft-Gault formula and to adjust the dose of the drug according to the information provided by the producer. This action is in line with the generally accepted recommendations for the prevention and slowing of the progression of CKD, where one of the medical measures is to avoid nephrotoxic effects of the applied therapy and meets one of the main ethical postulates in medicine, ie, "Primum non nocere."

\section{Acknowledgments}

This study was supported by the Wroclaw Medical University grant (No. SUB.A310.21.068).

\section{Disclosure}

The authors report no conflicts of interest in this work.

\section{References}

1. National Kidney Foundation: K/DOQI clinical practice guidelines for chronic kidney disease: evaluation, classification, and stratification. Kidney disease outcome quality initiative. Am J Kidney Dis. 2002;39 (2 Suppl 2):S1-S246.

2. Nojima J, Meguro S, Ohkawa N, et al. 1 One-year eGFR decline rate is a good predictor of prognosis of renal failure in patients with type 2 diabetes. Jpn Acad Ser B Phys Biol Sci. 2017;93(9):746-754. doi:10.2183/pjab.93.046

3. Rutkowski B. Przewlekła choroba nerek $(\mathrm{PChN})$ - wyzwanie XXI wieku. Przew Lek. 2007;2(94):80-87.

4. Schiepatti A, Remuzzi G. Chronic renal diseases as a public health problem: epidemiology, social, and economic implications. Kidney Int. 2005;68(Supplement 98):S7-S10. doi:10.1111/j.1523-1755.20 05.09801.x

5. Levey AS, Coresh J, Bolton K, et al. K/DOQI clinical practice guidelines for chronic kidney disease: evaluation, classification, and stratification. Am J Kidney Dis. 2013;62:i-ii+.
6. Rutkowski B. Wczesne rozpoznawanie przewlekłej choroby nerek (PChN). Medycyna Po Dyplomie. 2008;12:99-103.

7. Zdrojewski Ł, Rutkowski B. MDRD czy CKD-EPI rewolucja czy ewolucja. Forum Nefrologiczne. 2014;7(1):38-44.

8. Makris K, Spanou L. Acute kidney injury: definition, pathophysiology and clinical phenotypes. Clin Biochem Rev. 2016;37(2):85-98.

9. Hosten AO. BUN and Creatinine. In: Walker HK, Hall WD, Hurst JW, editors. Clinical Methods: The History, Physical, and Laboratory Examinations. 3rd ed. Boston: Butterworths; 1990.

10. Branten AJ, Vervoort G, Wetzels JF. Serum creatinine is a poor marker of GFR in nephrotic syndrome. Nephrol Dial Transplant. 2005;20(4):707-711. doi:10.1093/ndt/gfh719

11. Cockcroft DW, Gault MH. Prediction of creatinine clearance from serum creatinine. Nephron. 1976;16:31-41. doi:10.1159/000180580

12. Millar JA. The Cockroft and Gault formula for estimation of creatinine clearance: a friendly deconstruction. $N$ Z Med J. 2012;125 (1350):119-122.

13. Levey AS, Bosch JP, Lewis JB. A more accurate method to estimate glomerular filtration rate from serum creatinine: a new prediction equation. Modification of Diet in Renal Disease Study Group. Ann Intern Med. 1999;130:461-470. doi:10.7326/0003-4819-130-6199903160-00002

14. National Kidney Foundation. Frequently asked questions about GFR estimates" 2014 Inc. 12-10-4004_ABE. Available from: www.kid ney.org. Accessed November 15, 2021.

15. Committee for Medicinal Products for Human use (CHMP) Guideline on the evaluation of the pharmacokinetics of medicinal products in patients with decreased renal function. EMA/CHMP/ 83874/2014; 2015.

16. CKD \& Drug Dosing: Information for Providers. Estimation of Kidney Function for Prescription Medication Dosage in Adults, National Institute of Diabetes and Digestive and Kidney Diseases (NIDDK). Available form: https://www.niddk.nih.gov/ research-funding/research-programs/kidney-clinical-research-epide miology/laboratory/ckd-drug-dosing-providers. Reviewed March 2021.

17. Stevens LA, Nolin TD, Richardson MM. ChronicKidneyDisease EpidemiologyCollaboration (CKD-EPI). Comparison of drug dosing recommendations based on measured GFR and kidney function estimating equations. Am $J$ Kidney Dis. 2010;55(4):660-670. doi:10.1053/j.ajkd.2009.12.011

18. Levey AS, Greene T, Kusek J, Beck GJ, Group MS. A simplified equation to predict glomerular filtration rate from serum creatinine [Abstract]. J Am Soc Nephrol. 2000;11:A0828.

19. Stevens LA, Coresh J, Greene T, Levey AS. Assessing kidney function - measured and estimated glomerular filtration rate. $N$ Engl $J$ Med. 2006;354:2473-2483.

20. Stevens LA, Manzi J, Levey AS, et al. Impact of creatinine calibration on performance of GFR estimating equations in a pooled individual patient database. Am J Kidney Dis. 2007;50(1):21-35. doi:10.1053/j.ajkd.2007.04.004

21. Levey AS, Coresh J, Greene T, et al. Using standardized serum creatinine values in the modification of diet in renal disease study equation for estimating glomerular filtration rate. Ann Intern Med. 2006;145(4):247254. doi:10.7326/0003-4819-145-4-200608150-00004

22. Levey AS, Coresh J, Greene T, et al. Expressing the Modification of Diet in Renal Disease Study equation for estimating glomerular filtration rate with standardized serum creatinine values. Clin Chem. 2007;53(4):766-772. doi:10.1373/clinchem.2006.077180

23. Levey AS, Stevens LA, Schmid CH. A new equation to estimate glomerular filtration rate. Ann Intern Med. 2009;150:604-612. doi:10.7326/0003-4819-150-9-200905050-00006

24. Inker LA, Levey AS. Pro: estimating GFR using the chronic kidney disease epidemiology collaboration (CKD-EPI) 2009 creatinine equation: the time for change is now. Nephrol Dial Transplant. 2013;28:1390-1396. doi:10.1093/ndt/gft003 
25. Delanaye P, Pottel H, Botev R, Inker LA, Levey AS. Con: should we abandon the use of the MDRD equation in favour of the CKD-EPI equation? Nephrol Dial Transplant. 2013;28:1396-1403. doi:10.10 93/ndt/gft006

26. Drabczyk R. Czy GFR zmienia się fizjologicznie z wiekiem”, portal Medycyna Praktyczna, Medycyna Rodzinna; 2012.

27. Breshears MA, Confer AW. The Urinary System Pathologic Basis of Veterinary Disease. 6th ed. St Louis:Elsevier; 2017:617-681.e1. DOI:10.1016/B978-0-323-35775-3.00011-4

28. Hommos MS, Glassock RJ, Rule AD. Structural and functional changes in human kidneys with healthy aging. J Am Soc Nephrol. 2017;28(10):2838-2844. doi:10.1681/ASN.2017040421

29. Stevens LA, Nolin T, Richardson M, et al. Comparison of drug dosing recommendations based on measured GFR and kidney function estimating equations. Am J Kid Dis. 2009;54(1):33-42. doi:10.1053/j.ajkd.2009.03.008

30. Ficek J, Chudek J. Dawkowanie leków kardiologicznych w przewlekłej chorobie nerek". Choroby Serca I Naczyn. 2013;10 (5):270-275.

31. National Kidney Disease Education Program. Chronic kidney disease and drug dosing: information for providers; 2009. Available from: http://www.nkdep.nih.gov/professionals/drugdosing-information.htm. Accessed June 11, 2010.

32. Kuźniar-Placek J, Dereziński T, Wolf J, Jaroszyński A. Ocena funkcji nerek u osób w wieku podeszłym. Forum Medycyny Rodzinnej. 2015;9(2):112-114.
33. Matzke GR, Aronoff GR, Atkinson AJ Jr, et al. Drug dosing consideration in patients with acute and chronic kidney disease-a clinical update from Kidney Disease: improving Global Outcomes (KDIGO). Kidney Int. 2011;80:1122-1137. doi:10.1038/ki.2011.322

34. Kasiske B, Keane W. Laboratory assessment in kidney disease: clearance, urinalysis, and renal biopsy. In: Brenner B, editor. Brenner and Rector's the Kidney. 6th ed. Philadelphia, PA: WB Saunders; 2000:1129-1170.

35. Bauer JH, Brooks CS, Burch RN. Clinical appraisal of creatinine clearance as a measurement of glomerular filtration rate. Am J Kidney Dis. 1982;2:337-346. doi:10.1016/S0272-6386(82)80091-7

36. Walser M. Assessing renal function from creatinine measurements in adults with chronic renal failure. Am J Kidney Dis. 1998;32:23-31. doi:10.1053/ajkd.1998.v32.pm9669420

37. Stevens LA, Coresh J, Feldman HI. Evaluation of the modification of diet in renal disease study equation in a large diverse population. $J$ Am Soc Nephrol. 2007;18:2749-2757. doi:10.1681/ASN.2007020199

38. Froissart M, Rossert J, Jacquot C. Predictive performance of the modification of diet in renal Disease and Cockcroft-Gault equations for estimating renal function. J Am Soc Nephrol. 2005;16:763-773. doi:10.1681/ASN.2004070549

39. Cirillo MG. Rationale, pros and cons of GFR estimation: the Cockcroft-Gault and MDRD equation. Giornale Italiano di Nefrologia. 2009;26(3):310-317. PMID: 19554528.
Clinical Interventions in Aging

\section{Publish your work in this journal}

Clinical Interventions in Aging is an international, peer-reviewed journal focusing on evidence-based reports on the value or lack thereof of treatments intended to prevent or delay the onset of maladaptive correlates of aging in human beings. This journal is indexed on PubMed Central, MedLine, CAS, Scopus and the Elsevier

\section{Dovepress}

Bibliographic databases. The manuscript management system is completely online and includes a very quick and fair peer-review system, which is all easy to use. Visit http://www.dovepress.com/ testimonials.php to read real quotes from published authors. 